\title{
Study to establish visual acuity norms with Teller Acuity Cards II for infants from southern China
}

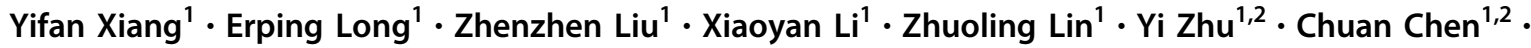 \\ Haotian Lin $\mathbb{D}^{1,3}$
}

Received: 28 April 2019 / Revised: 28 October 2020 / Accepted: 10 November 2020 / Published online: 24 November 2020

(c) The Author(s), under exclusive licence to The Royal College of Ophthalmologists 2020

\begin{abstract}
Objectives To establish the norms of binocular and monocular acuity and interocular acuity differences for southern Chinese infants and compare these norms with the results for northern Chinese infants.

Methods A prospective, comparative, and noninterventional study was conducted from January to August 2018. Teller Acuity Cards II were used to determine the binocular and monocular acuity of infants. The tolerance intervals and limits with a stated proportion and probability were used to evaluate the norms of binocular and monocular acuity and interocular acuity differences. An unpaired $t$-test was used to compare the obtained norms with the reported northern Chinese norms.

Results The tolerance intervals of binocular acuity (mean acuity of 3.73, 7.35, and $12.01 \mathrm{cpd}$, respectively, at 12, 24, and 36 months), monocular acuity (mean acuity of $2.88,6.91$, and $10.75 \mathrm{cpd}$, respectively, at 12,24 , and 36 months), and interocular acuity differences (mean difference of $0.92,2.89$, and $3.99 \mathrm{cpd}$, respectively, at 12, 24, and 36 months) were obtained, exhibiting an increasing trend with age. The binocular visual acuity norms of southern Chinese infants were significantly lower than those in northern China ( 4.37 vs. $6.9 \mathrm{cpd}$ at 8 months and 7.35 vs. $26 \mathrm{cpd}$ at 24 months $)(P=0.011)$. Conclusions Northern and southern Chinese infants exhibited distinct acuity norms and visual development patterns. The establishment of population-specific visual acuity norms is necessary for current populations of infants from different regions.
\end{abstract}

\section{Introduction}

The development of normal visual function and ocular structures is important for the early acquisition of visual information and intelligence development [1-4]. Visual assessments, particularly assessments performed during the first year of life, are clinically important because

Supplementary information The online version of this article (https:// doi.org/10.1038/s41433-020-01314-y) contains supplementary material, which is available to authorized users.

Haotian Lin

gddlht@aliyun.com

1 State Key Laboratory of Ophthalmology, Zhongshan Ophthalmic Center, Sun Yat-sen University, Guangzhou, China

2 Department of Molecular and Cellular Pharmacology, University of Miami Miller School of Medicine, Miami, USA

3 Center of Precision Medicine, Sun Yat-Sen University, Guangzhou, China early detection and timely interventions to correct abnormal visual function can prevent long-term visual impairment [5-10]. The establishment of visual acuity (VA) norms can help clinicians monitor visual development patterns, facilitate the diagnosis of visual abnormalities, and enable the evaluation of therapeutic effects $[11,12]$.

Infant vision assessments are derived from a report of Fantz published in 1958 that showed for the first time that the pattern preference of infants could be successfully measured to evaluate VA [13]. Subsequently, Teller and McDonald created the acuity card procedure in 1985. One year later, Teller designed the Vistech-Teller Acuity Cards (TAC), which greatly improved the practicality of vision assessments in infants [14, 15]. Initial binocular and monocular norms were obtained using the original TAC in several studies [11, 16-22]. In 1995, the results of a study of 646 infants were used to modified the test procedure, and binocular and monocular norms were obtained [12]. The Teller Acuity Cards II (TAC II) were subsequently accepted as a standard vision test for infants, and the VA norms 
established with the original TAC have been used as references up to present [23].

VA norms must be established for Chinese infants for the following reasons. More than 15 million infants are born each year in China, and they account for $1 \%$ of the total Chinese population [24]. The recent implementation of the two-child policy and the tendency toward later marriage and childbirth lead to an increased risk of congenital defects, including many ocular diseases [25-27]. However, the VA norms for Chinese infants have not been well-established. So far, only one study has obtained the VA norms for northern Chinese infants [28]. Generally, a universally applicable norm requires data collection on a massive scale, yet previous studies that have attempted to obtain new norms have been constrained by the limited data on infants from few districts.

In this study, we aim to establish VA norms of binocular and monocular acuity and interocular acuity differences (IADs) for infants from southern China using the TAC II to update the current standards for diagnosis and treatment evaluations. In addition, we compare the VA norm for southern Chinese infants with the previously established VA norm for northern Chinese infants to investigate the potential regional differences in VA development.

\section{Materials and methods}

A prospective study was conducted at the Zhongshan Ophthalmic Center (ZOC), Guangdong, China. This study was approved by the Ethical Review Committee of ZOC, and the tenets of the Declaration of Helsinki were followed throughout this study.

\section{Study sample}

Overall, 218 infants aged 0-36 months were enrolled from Guangdong, southern China. The inclusion criteria were as follows: (1) the infants weighed $2.5-4.0 \mathrm{~kg}$ and had an age of 37-42 weeks of gestation at birth; (2) the infants were younger than 37 months; and (3) no obvious abnormalities were found in eye position, eye movement, and anterior segment examination. The exclusion criteria were as follows: (1) a previous diagnosis of an ocular disease; or (2) a previous diagnosis of congenital diseases. The test procedure was described to the guardians of the infants in detail, and only children whose guardians signed the informed consent document were tested.

\section{Test procedure}

Each child was tested in a quiet room that was specifically designated for testing with the TAC II at the ZOC. A standardized apparatus and procedure were adopted: the apparatus consisted of a stage and a video recorder placed directly facing the infants. The stage was used to minimize interference from the ophthalmologist, and the video recorder was used to record all test processes for quality inspection and to ensure the reliability of the test results. The test procedure followed the instructions of the TAC II handbook, which was provided by the University of Washington, and the contrast settings of the cards were $\sim 60-70 \%$ [29]. Specifically, infants were either held or seated alone at $38 \mathrm{~cm}$ (birth to 6 months) or $55 \mathrm{~cm}$ (7-36 months) from the acuity cards while facing the tester. The tester attempted to attract the infant's attention. When the infant looked straight ahead, the tester held up a card. Based on a variety of cues, including fixation, pointing, and/ or verbalization, the tester made an initial decision regarding whether the child could see the grating. Coarser or finer gratings were then presented, and this process was repeated until the tester could determine the finest grating that the child could see. This grating indicated the infant's VA. The monocular test was performed after the binocular test. The initial eye examined in the monocular test was randomly selected, and a single eye patch was used in the monocular test. All tests were performed and recorded by the same ophthalmologist (XL), who had been well-trained in administering the TAC II tests following the instructions of the TAC II handbook.

\section{Statistical analysis}

After a transformation of the data to determine the acuity at $55 \mathrm{~cm}$ and the calculation of the log values of the VA scores, all visual data were analyzed using $\mathrm{R}$ 3.5.1. The concept of a "tolerance interval" was used to illustrate the normative range [14]. This method describes a fixed proportion of the population with a stated confidence, including both one- and two-sided intervals. The endpoints of the tolerance interval are called tolerance limits and are calculated with the equations $\mathrm{TL}_{1}=$ mean $-\mathrm{K} \times \mathrm{SD}$ and $\mathrm{TL}_{\mathrm{u}}=$ mean $+\mathrm{K} \times \mathrm{SD}$. $\mathrm{TL}_{1}$ and $\mathrm{TL}_{\mathrm{u}}$ represent the lower and upper limits, respectively; $\mathrm{K}$ is a constant based on the type of tolerance interval, the number of the subjects, the expected probability, and the proportion; SD is the standard deviation of the mean [30]. In our study, a two-sided interval was used to calculate the lower and upper limits with a fixed proportion and confidence level, according to the number of participants in each group. A proportion of $90 \%$ and a confidence level of $95 \%$ were adopted for most groups. The binocular norms for the first two age groups (the 0-3 and 4-6 months groups) and the IAD for the 28-30 months group were calculated with a proportion of $90 \%$ and a confidence of $90 \%$. The IAD norms for the first three age groups (0-6, 7-12, and 13-18 months groups) were 
calculated with a proportion of $90 \%$ and a confidence of $80 \%$ according the group number. An unpaired $t$-test was used to compare the differences between the binocular and monocular norms, the diversity of the IADs in our results, and the discrepancy between northern and southern China. $P<0.05$ was considered statistically significant.

\section{Results}

Overall, 218 infants (107 females and 111 males) from southern China were enrolled and 215 (98.6\%) infants completed the binocular test. Monocular data were obtained from 208 eyes of $108(50.2 \%)$ infants, and 100 infants completed the monocular test for both eyes.

\section{Binocular and monocular norms of southern China}

The binocular tolerance interval was based on the VA scores of 215 infants, aged 2-36 months, and the monocular interval was based on the VA scores of 208 eyes. The binocular and monocular normative ranges, including the mean acuity and upper and lower limits for the different age groups, are shown in Table 1. The increasing trends of

Table 1 Norms of different age groups.

\begin{tabular}{lclll}
\hline $\begin{array}{l}\text { Age } \\
\text { (months) }\end{array}$ & Number & $\begin{array}{l}\text { Mean acuity } \\
\text { (cyc/deg) }\end{array}$ & $\begin{array}{l}\text { Lower limit } \\
\text { (cyc/deg) }\end{array}$ & $\begin{array}{l}\text { Upper limit } \\
\text { (cyc/deg) }\end{array}$ \\
\hline \multicolumn{2}{l}{ Binocular norms } & & & \\
$2-3$ & 8 & 1.18 & 0.41 & 3.42 \\
$4-6$ & 14 & 2.32 & 0.86 & 6.26 \\
$7-9$ & 25 & 4.37 & 2.18 & 8.74 \\
$10-12$ & 19 & 3.73 & 1.44 & 9.66 \\
$13-15$ & 19 & 4.62 & 1.67 & 12.78 \\
$16-18$ & 15 & 4.37 & 1.28 & 14.92 \\
$19-21$ & 13 & 5.82 & 1.34 & 25.18 \\
$22-24$ & 12 & 7.35 & 1.58 & 34.22 \\
$25-27$ & 19 & 6.93 & 3.21 & 20.80 \\
$28-30$ & 12 & 10.68 & 3.64 & 31.37 \\
$31-33$ & 24 & 10.02 & 2.65 & 37.88 \\
$34-36$ & 35 & 12.01 & 3.10 & 46.50 \\
Monocular & norms & & & \\
$2-6$ & 12 & 1.97 & 0.55 & 7.06 \\
$7-12$ & 11 & 2.88 & 0.91 & 9.17 \\
$13-18$ & 13 & 4.04 & 1.72 & 9.50 \\
$19-21$ & 10 & 4.39 & 1.15 & 16.78 \\
$22-24$ & 14 & 6.91 & 2.08 & 22.91 \\
$25-27$ & 29 & 5.91 & 2.13 & 16.41 \\
$28-30$ & 19 & 7.95 & 3.11 & 20.31 \\
$31-33$ & 41 & 8.77 & 2.01 & 38.19 \\
$34-36$ & 59 & 10.75 & 4.75 & 24.34 \\
\hline
\end{tabular}

the binocular and monocular norms are presented in Fig. 1. Both binocular and monocular norms exhibited steady and rapid growth after birth. The duration of the rapid growth for the monocular norms (nearly 1 year) was longer than that for the binocular norms ( 8 months). Overall, the mean binocular acuity was slightly higher than that of monocular acuity, but the difference between the binocular and monocular VA norms was not significant.

\section{IADs with slow growth}

Overall, 100 infants, aged 2-36 months, completed the monocular test for both eyes, and the IADs were calculated. IADs can be classified into three types as follows: the VA of the oculus dexter is equal to that of the oculus sinister $(\mathrm{VOD}=\mathrm{VOS})$; the VA of the oculus dexter is higher than that of the oculus sinister (VOD > VOS); and the VA of the oculus dexter is lower than that of the oculus sinister (VOD $<$ VOS). The number of participants classified in each age group is shown in Supplementary Table 1. Each IAD type accounts for approximately one-third of all participants. The mean absolute IADs of the VOD > VOS type and the VOD $<$ VOS type are presented in Supplementary Table 1, and both types exhibited a rising tendency with age and accounted for approximately one-third of each age group. There was no statistically significant difference between the two IAD types. Table 2 and Fig. 2 show the mean absolute IADs and their upper limits in different age groups. The upper limits of the IADs exhibited a slow growth with age and became stable at the third year.

\section{Regional differences of VA norms}

A study performed in northern China revealed VA norms of 5-24 months, based on 241 infants from middle-to-high income families in Beijing [28]. The norms in our study were compared with previous results from northern China, and both norms were obtained following the test instructions for TAC II equipped with a stage. A significant

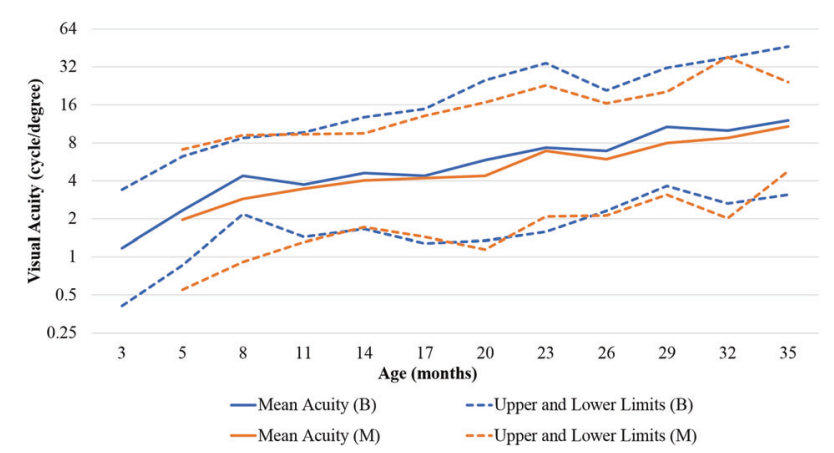

Fig. 1 Binocular and monocular mean acuities and tolerance limits. B binocular, $\mathrm{M}$ monocular. 
Table 2 Norms of IADs in different age groups.

\begin{tabular}{llll}
\hline Age (months) & Number & $\begin{array}{l}\text { Mean absolute IAD } \\
\text { (cyc/deg) }\end{array}$ & $\begin{array}{l}\text { Upper limit } \\
\text { (cyc/deg) }\end{array}$ \\
\hline $2-6$ & 5 & 0.68 & 2.11 \\
$7-12$ & 5 & 0.92 & 3.86 \\
$13-18$ & 6 & 1.42 & 3.69 \\
$19-24$ & 11 & 2.89 & 7.17 \\
$25-27$ & 14 & 2.06 & 7.60 \\
$28-30$ & 9 & 3.82 & 7.08 \\
$31-33$ & 18 & 3.04 & 8.35 \\
$34-36$ & 32 & 3.99 & 8.20 \\
\hline
\end{tabular}

$I A D$ interocular acuity difference.

${ }^{a}$ Interocular acuity data did not assume that the visual acuity of the oculus dexter was equal to the oculus sinister when calculating the mean absolute IAD.

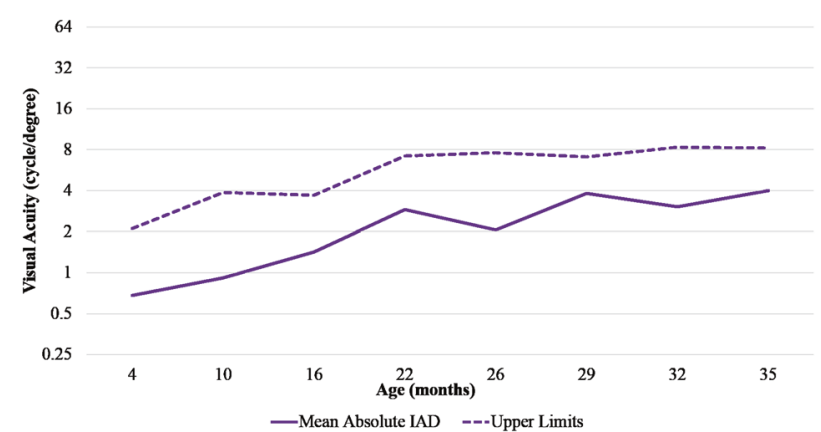

Fig. 2 Mean absolute IAD and upper limits. IAD interocular acuity difference.

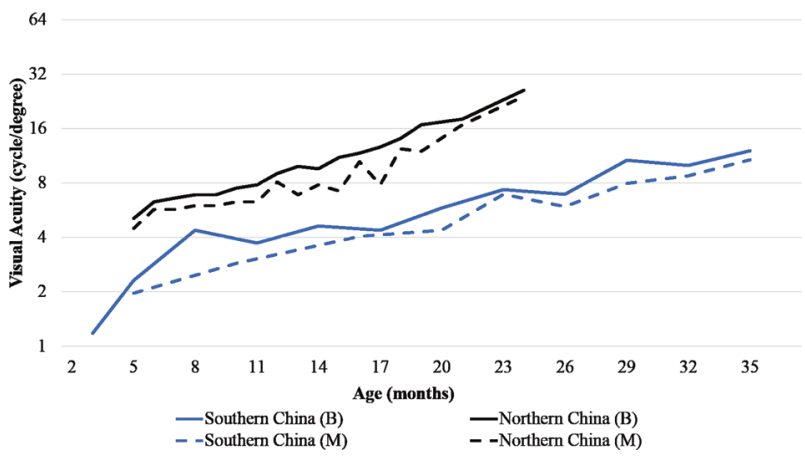

Fig. 3 Mean binocular and monocular acuity of infants from southern China and northern China. B binocular, M monocular.

difference between VA values was observed between the two regions, as shown in Fig. $3(P=0.011$ for binocular acuity, $P=0.099$ for mean monocular acuity). The mean binocular and monocular acuities of infants in northern China obviously surpassed those of infants in southern China, with a superiority ranging from 50 to $200 \%$. The mean acuity of infants from northern China approached the normal acuity level of adults at 24 months ( $26 \mathrm{cpd}, 0.83$ ), while most infants from southern China were still in a low vision state (7.35 cpd, 0.24). In addition, the mean VA of infants from northern and southern China was 6.9 and 4.37 cpd (1.57 times), respectively, at $\sim 8$ months and 26 and $7.35 \mathrm{cpd}$ (3.54 times), respectively, at 24 months, thus indicating an increasing VA gap with age.

\section{Discussion}

The lack of VA norms can impede the diagnosis and treatment of visual abnormalities in infants. Thus far, only VA norms for northern Chinese infants have been documented. However, discrepancies in the VA norms from reported studies highlight the importance of establishing more orientated and specific VA norms [16-20, 22]. Moreover, additional data are required to verify the applicability of previous norms and establish a more integrated set of norms. In this study, we prospectively collected VA data from 215 healthy infants from southern China and analyzed these data using the TAC II. We then calculated new norms applicable to southern Chinese infants and compared these norms to the norms for northern Chinese infants.

We showed that the VA norms of binocular and monocular acuity for infants in southern China exhibited a steady growth after birth, although the growth rate of VA slowed down after the first year. This finding can be explained by the change of axial length: infants are physiologically hyperopic at birth and gradually approach emmetropization with ocular development and axial length growth. The axial length growth rate primarily determines the time needed to reach emmetropization and the increment speed of VA. Previous reports have indicated that axial length exhibits a rapid initial growth during the first 12 months after birth and increases slowly from ages 1 to 3 years [31,32], which is similar to the growth pattern of VA. Therefore, we speculate that the "initially rapid and then slow" growth pattern of VA norms is primarily influenced by the axial length growth rate.

Here, we establish the norms for IAD for Chinese infants for the first time using the TAC II. The mean absolute IAD and upper limits were similar for the VOD $>$ VOS and VOD $<$ VOS types, and both types progressively increase and approach a steady state at 3 years of age. However, systematic variations in the mean IAD have been reported in several studies, indicating that IAD is highest at birth and gradually decreases with age [33-35]. Because each type of IAD $(\mathrm{VOD}=\mathrm{VOS}, \mathrm{VOD}>\mathrm{VOS}$, and $\mathrm{VOD}<\mathrm{VOS})$ accounted for approximately one-third of all participants in our study and obvious IADs were observed in previous studies [33-36], we assume that the development of both 
eyes is not always identical. Patterns of similar acuity, better oculus dexter acuity, or better oculus sinister acuity are all possible because the two eyes may be in slightly different developmental stages during early age when acuity develops rapidly [33]. In addition, a remarkable double rise in IAD for the same age group was revealed over 10 years $[34,35]$, which indicates that the developmental differences between two eyes become larger, and infants with IAD can be considered normal only if the IAD is within the upper limits [34].

The results for southern and northern Chinese infants exhibited a considerable gap in acuity levels and the methodologies of both studies were the same. This inconsistency in VA norms was also detected during the establishment of norms with the original TAC [12, 16-21]. The differences in VA norms may be related to the test procedures and test conditions, or the income of the infant's family $[11,12,37]$. However, more intrinsic reasons, such as the incidence of ocular disease and environment differences among different regions, may also contribute to the differences in VA development [38-41]. For example, the incidence of visual impairment in adults in southern China $(5.38 \%)$ is much higher than that in northern China $(0.1 \%)$ [40, 41]. In addition, the prevalence of refractive error in children from developed cities in southern China (33.22\%) is greater than that of developed cities in northern China $(25.5 \%)[38,42]$. Therefore, we do not exclude the possibility that the differences of VA development between infants from southern and northern China may be attributed to the susceptibility of ocular disease. Consequently, we speculate that the regional differences in visual development are non-negligible in the application of visual norms.

\section{Limitations}

The limitations of our research should be considered. First, the IAD data from the early age groups are limited; therefore, the upper limits of the IADs require additional investigation to ensure their accuracy. Second, the specific explanation for regional differences in VA is still unclear. Further studies are warranted to investigate the factors that generate the regional variety.

\section{Conclusions}

Our study is the first study to define the VA norms for both binocular and monocular acuity for southern Chinese infants and the IADs for Chinese infants. VA norms and early visual development processes are diverse among different regions and time points, thus confirming the necessity of establishing population-specific VA norms for infants.

\section{Summary}

\section{What was known before}

- The lack of visual acuity (VA) norms can impede the diagnosis and treatment of visual abnormalities in infants.

- A universally applicable VA norm requires data collection on a massive scale.

- The VA norms for Chinese infants have not been wellestablished and only one study has obtained the VA norms for northern Chinese infants.

\section{What this study adds}

- Our study is the first study to define VA norms of IADs for Chinese infants and to define VA norms of both binocular and monocular acuity for southern Chinese infants.

- There is an obvious discrepancy of VA norms between northern and southern Chinese infants.

- The establishment of population-specific VA norms is necessary for infants from different regions.

Acknowledgements The authors are grateful to all participants for supporting our study.

Funding This study was funded by grants from the National Natural Science Foundation of China (91546101), the Guangdong Provincial Natural Science Foundation for Distinguished Young Scholars of China (2014A030306030), and the Outstanding Young Teacher Cultivation Projects in Guangdong Province (YQ2015006). The sponsors of the study played no role in the study protocol design; data collection, analysis, or interpretation; manuscript preparation; or the decision to submit the manuscript for publication.

\section{Compliance with ethical standards}

Conflict of interest The authors declare that they have no conflict of interest.

Publisher's note Springer Nature remains neutral with regard to jurisdictional claims in published maps and institutional affiliations.

\section{References}

1. Roizen N, Kasza K, Karrison T, Mets M, Noble AG, Boyer K, et al. Impact of visual impairment on measures of cognitive function for children with congenital toxoplasmosis: implications for compensatory intervention strategies. Pediatrics. 2006;118: e379-390.

2. Brémond-Gignac D, Copin H, Lapillonne A, Milazzo S. Visual development in infants: physiological and pathological mechanisms. Curr Opin Ophthalmol. 2011;22:S1-8. 
3. Dallaire R, Muckle G, Rouget F, Kadhel P, Bataille H, Guldner L, et al. Cognitive, visual, and motor development of 7-month-old Guadeloupean infants exposed to chlordecone. Environ Res. 2012;118:79-85.

4. Elyashiv SM, Shabtai EL, Belkin M. Correlation between visual acuity and cognitive functions. Br J Ophthalmol. 2014;98:129-32.

5. Jacobson SG, Mohindra I, Held R. Development of visual acuity in infants with congenital cataracts. $\mathrm{Br} \mathrm{J}$ Ophthalmol. 1981;65:727-35.

6. Wiesel TN. Postnatal development of the visual cortex and the influence of environment. Nature. 1982;299:583-91.

7. Lewis TL, Maurer D, Brent HP. Effects on perceptual development of visual deprivation during infancy. $\mathrm{Br} \mathrm{J}$ Ophthalmol. 1986;70:214-20.

8. Sener EC, Mocan MC, Gedik S, Ergin A, Sanaç AS. The reliability of grading the fixation preference test for the assessment of interocular visual acuity differences in patients with strabismus. J AAPOS. 2002;6:191-4.

9. Lewis TL, Maurer D. Effects of early pattern deprivation on visual development. Optom Vis Sci. 2009;86:640-6.

10. Livingstone IA, Lok AS, Tarbert C. New mobile technologies and visual acuity. Conf Proc IEEE Eng Med Biol Soc. 2014;2014:2189-92.

11. Mayer DL, Beiser AS, Warner AF, Pratt EM, Raye KN, Lang JM. Monocular acuity norms for the Teller Acuity Cards between ages one month and four years. Invest Ophthalmol Vis Sci. 1995;36:671-85.

12. Salomão SR, Ventura DF. Large sample population age norms for visual acuities obtained with Vistech-Teller Acuity Cards. Invest Ophthalmol Vis Sci. 1995;36:657-70.

13. Fantz RL. Pattern vision in young infants. Psychological Rec. 1958;8:43-47.

14. McDonald MA, Dobson V, Sebris SL, Baitch L, Varner D, Teller DY. The acuity card procedure: a rapid test of infant acuity. Invest Ophthalmol Vis Sci. 1985;26:1158-62.

15. Teller DY, McDonald MA, Preston K, Sebris SL, Dobson V. Assessment of visual acuity in infants and children: the acuity card procedure. Dev Med Child Neurol. 1986;28:779-89.

16. Brown AM, Yamamoto M. Visual acuity in newborn and preterm infants measured with grating acuity cards. Am J Ophthalmol. 1986;102:245-53.

17. McDonald M, Ankrum C, Preston K, Sebris SL, Dobson V. Monocular and binocular acuity estimation in 18- to 36-montholds: acuity card results. Am J Optom Physiol Opt. 1986;63:181-6.

18. McDonald M, Sebris SL, Mohn G, Teller DY, Dobson V. Monocular acuity in normal infants: the acuity card procedure. Am J Optom Physiol Opt. 1986;63:127-34.

19. Van Hof-van Duin J, Mohn G. The development of visual acuity in normal fullterm and preterm infants. Vis Res. 1986;26:909-16.

20. Dobson V, Schwartz TL, Sandstrom DJ, Michel L. Binocular visual acuity of neonates: the acuity card procedure. Dev Med Child Neurol. 1987;29:199-206.

21. Kohl P, Samek M. Refractive error and preferential looking visual acuity in infants 12-24 months of age: year 2 of a longitudinal study. J Am Optom Assoc. 1988;59:686-90.
22. Courage ML, Adams RJ. Visual acuity assessment from birth to three years using the acuity card procedure: cross-sectional and longitudinal samples. Optom Vis Sci. 1990;67:713-8.

23. Clifford CE, Haynes BM, Dobson V. Are norms based on the original Teller Acuity Cards appropriate for use with the new Teller Acuity Cards II. J AAPOS. 2005;9:475-9.

24. National Bureau of Statistics of China. Birth rate, death rate, and natural growth rate of population. http://data.stats.gov.cn/.

25. Kujansuu E, Kivinen S, Tuimala R. Pregnancy and delivery at the age of forty and over. Int J Gynaecol Obstet. 1981;19:341-5.

26. Ellegren $\mathrm{H}$. Characteristics, causes and evolutionary consequences of male-biased mutation. Proc Biol Sci. 2007;274:1-10.

27. Sartorius GA, Nieschlag E. Paternal age and reproduction. Hum Reprod Update. 2010;16:65-79.

28. Qiu Y, Li XQ, Yan XM. Evaluation of grating visual acuity development in normal infants. Zhonghua Yan Ke Za Zhi. 2011;47:995-1000.

29. Teller DY, Dobson V, Mayer DL. Teller Acuity Cards ${ }^{\mathrm{TM}}$ II Handbook. Revised Edition. (University of Washington, 2005).

30. Dixon WJ, Massey FJ. Introduction to statistical analysis. 2nd ed. New York: McGraw-Hill; 1957.

31. Gordon RA, Donzis PB. Refractive development of the human eye. Arch Ophthalmol. 1985;103:785-9.

32. Hussain RN, Shahid F, Woodruff G. Axial length in apparently normal pediatric eyes. Eur J Ophthalmol. 2014;24:120-3.

33. Birch EE. Infant interocular acuity differences and binocular vision. Vis Res. 1985;25:571-6.

34. Salomão SR, Ejzenbaum F, Berezovsky A, Sacai PY, Pereira JM. Age norms for monocular grating acuity measured by sweep-VEP in the first three years of age. Arq Bras Oftalmol. 2008;71:475-9.

35. Costa MF, de Cássia Rodrigues Matos França V, Barboni M, Ventura DF. Maturation of binocular, monocular grating acuity and of the visual interocular difference in the first 2 years of life. Clin EEG Neurosci. 2018;49:159-70.

36. Atkinson J, Braddick O, Pimm-Smith E. 'Preferential looking' for monocular and binocular acuity testing of infants. Br J Ophthalmol. 1982. 66:264-8.

37. Leone JF, Mitchell P, Kifley A, Rose KA, Sydney childhood eye Studies. Normative. visual acuity in infants and preschool-aged children in Sydney. Acta Ophthalmol. 2014;92:e521-9.

38. He M, Zeng J, Liu Y, Xu J, Pokharel GP, Ellwein LB. Refractive error and visual impairment in urban children in southern china. Invest Ophthalmol Vis Sci. 2004;45:793-9.

39. He M, Zheng Y, Xiang F. Prevalence of myopia in urban and rural children in mainland China. Optom Vis Sci. 2009;86:40-44.

40. You QS, Xu L, Yang H, Wang YX, Jonas JB. Five-year incidence of visual impairment and blindness in adult Chinese the Beijing Eye Study. Ophthalmology. 2011;118:1069-75.

41. Wang L, Huang W, He M, Zheng Y, Huang S, Liu B, et al. Causes and five-year incidence of blindness and visual impairment in urban Southern China: the Liwan Eye Study. Invest Ophthalmol Vis Sci. 2013;54:4117-21.

42. Zhao J, Pan X, Sui R, Munoz SR, Sperduto RD, Ellwein LB. Refractive error study in children: results from Shunyi District, China. Am J Ophthalmol. 2000;129:427-35. 